\title{
Agregação de valor e distribuição de riqueza aos produtores rurais: o caso de uma cooperativa de cafeicultores
}

\author{
Adding value and distribution of value added to farmers: the case of a cooperative of \\ coffee growers
}

\begin{abstract}
Resumo
O presente artigo tem como objetivo investigar qual é a agregação de valor e a distribuição de riqueza das cooperativas agropecuárias. Para que a cooperativa cumpra a sua função é necessária a geração de riqueza por ela e sua distribuição. Portanto, analisar o desempenho de uma cooperativa somente por meio do modelo tradicional de avaliação de desempenho das organizações pode não ser o mais adequado, pois levam em consideração o lucro. Uma forma de analisar o desempenho econômico e social das organizações ocorre por meio da riqueza gerada, que consiste no valor econômico que é agregado aos bens e serviços adquiridos. A metodologia utilizada consiste na realização de um estudo de caso, onde analisou-se os Relatórios de Gestão e as Demonstrações do Valor Adicionado para os anos de 2010 a 2012 de uma cooperativa de cafeicultores. Os resultados confirmam a distribuição da riqueza gerada pela cooperativa estudada, resultando em um valor médio de benefícios por cooperado, em 2012, de R\$8.166,69.
\end{abstract}

Palavras-chave: Cooperativa, riqueza gerada, produtor rural associado.

\begin{abstract}
This paper aims to investigate what is the value added and distribution of agricultural cooperatives. For the cooperative fulfill its function to generate value and distribution is required. Therefore, analyzing the performance of a cooperative only through the traditional model of performance evaluation of the organizations may not be the most suitable as it takes into consideration the profit. One way to analyze the economic and social performance of organizations occurs through the value generated, which is the economic value that is added to the goods and services. The methodology consists of a case study, which analyzed the Management Reports and Value Added Statement for a coffee cooperative, analyzing 3 years, 2010 to 2012. The results confirm the distribution of value generated by the cooperative studied, resulting in an average value of benefits by associate, in 2012, of $R \$ 8,166.69$.
\end{abstract}

Keywords: Cooperatives, value added, associated farmers.

Recebido: 22/02/2016 Aceito: 23/03/2016

Anelise Krauspenhar Pinto Figari ${ }^{1}$ e Sigismundo Bialoskorski Neto ${ }^{2}$

${ }^{1}$ Faculdade de Economia, Administração e Contabilidade de Ribeirão Preto, Doutoranda em Controladoria e Contabilidade - akrauspenhar@fearp.usp.br- Av. Xv de Novembro, 1124, zona 1, apto 123, Maringá, PR

${ }^{2}$ Faculdade de Economia, Administração e Contabilidade de Ribeirão Preto, Doutorado em Economia Aplicada sig@usp.br 


\section{Introdução}

$\mathrm{A}$ s cooperativas ocupam posição de destaque em muitos setores, em especial na agricultura, como, por exemplo, são responsáveis por $50 \%$ da comercialização da produção agrícola da União Europeia, concentram $95 \%$ da produção de arroz e $90 \%$ da produção de peixe no Japão e comercializam mais de $30 \%$ da produção agrícola nos Estados Unidos (PRESNO, 2001).

O Brasil apresentava, aproximadamente, 7,61\% de seus estabelecimentos agropecuários associados em cooperativas. Esses estabelecimentos respondiam por $35 \%$ da renda da agricultura no mesmo período, menos de $10 \%$ do total dos estabelecimentos representaram mais de um terço da renda do setor (INSTITUTO BRASILEIRO DE GEOGRAFIA E ESTATÍSTICA - IBGE, 2012). Esses números demonstram a importância das cooperativas as quais impulsionam a atividade agropecuária, agregando valor e renda ao produtor (BIALOSKORSKI NETO; PINTO, 2012).

Uma evidência de que as cooperativas buscam maiores resultados no mercado em que estão inseridas, procurando ser competitivas, é a presença delas no ranking das 400 Maiores e Melhores Empresas do Agronegócio do Brasil da Revista Exame.

Mas cooperativas não possuem como finalidade o lucro assim como as demais organizações (BIALOSKORSKI NETO et al, 2006). As cooperativas existem como organização econômica intermediária, as quais prestam serviços aos seus associados, satisfazendo suas necessidades econômicas particulares (BIALOSKORSKI NETO, 2012).

Para que a cooperativa cumpra o seu papel é necessária a distribuição da riqueza gerada por ela de modo a agregar valor ao produtor rural associado. Assim, analisar desempenho de uma cooperativa agropecuária pode não ser o mais adequado quando da utilização do modelo tradicional de avaliação de desempenho, isso ocorre devido a alguns problemas inerentes à estrutura das cooperativas (BIALOSKORSKI NETO et al., 2006) e, pelo fato dos cálculos de avaliação de desempenho das empresas, em maioria, levarem em consideração o lucro (VIEIRA; SANTOS, 2007).

Uma forma de analisar o desempenho econômico e social das organizações ocorre por meio da riqueza gerada por elas, que consiste no valor econômico que é agregado aos bens e serviços adquiridos (TINOCO, 2006).

Dessa forma, a partir do entendimento de que as cooperativas agropecuárias são importantes aos produtores rurais, as quais agregam valor ao processo, gerando riqueza aos associados e à sociedade de uma forma geral, há a necessidade de considerar ao avaliar o desempenho de uma cooperativa a geração de riqueza dela e sua distribuição aos produtores rurais associados, pois sem agregar valor ao associado a cooperativa não cumpre o principal objetivo de sua existência.

Portanto, o trabalho propõe a seguinte questão de pesquisa: qual é a agregação de valor e a distribuição de riqueza das cooperativas agropecuárias brasileiras?

Dessa forma, o presente artigo possui como objetivo investigar qual é a agregação de valor e a distribuição de riqueza das cooperativas agropecuárias.

O presente trabalho encontra-se dividido em cinco partes, sendo: (i) introdução, (ii) referencial teórico, no qual se discutem a presença de cooperativas agropecuárias e a Demonstração do Valor Adicionado (DVA) (iii) aspectos metodológicos e apresentação da cooperativa estudada, (iv) análise dos resultados, no qual abordou-se a riqueza distribuída pela cooperativa e a DVA, e, for fim, as (v) considerações finais.

\section{Cooperativas Agropecuárias}

As cooperativas agropecuárias são organizações do setor do agronegócio no Brasil. O termo agronegócio, resultado da palavra utilizada em inglês agribusiness, surge com o objetivo de indicar as relações que ocorrem entre a produção agrícola, a atividade industrial e de distribuição. Ou seja, o termo passa a representar todo o sistema de base agrícola: insumos, agricultura, indústria, distribuição e consumo (ZYLBERSTAJN, 2013).

As cooperativas são consideradas sociedades civis de fins econômicos, mas não de fins lucrativos, dessa forma, apresentam distinções em suas funções econômica e social (BIALOSKORSKI NETO et al., 2006). São baseadas em valores de ajuda mútua e responsabilidade, democracia, igualdade, equidade e solidariedade (Organização de Cooperativas Brasileiras - OCB, 2015).

Existiam, no Brasil, para o ano de 2014, 6.582 cooperativas, as quais se encontram segmentadas 
por 13 ramos de atividades, o ramo agropecuário, de consumo, de crédito, educacional, especial, habitacional, de infraestrutura, mineral, de produção, de saúde, de trabalho, de transporte e de turismo e lazer (OCB, 2015).

O ramo agropecuário, objeto de estudo deste trabalho, é composto de cooperativas de produtores rurais, agropastoris ou de pesca. As cooperativas agropecuárias possuem como característica a prestação de serviços aos associados, como o recebimento e a comercialização da produção, o armazenamento e a industrialização desta (Aliança Cooperativa Internacional - ICA, 2015).

Existem 1.543 cooperativas no ramo agropecuário brasileiro, valor este que corresponde a $23,44 \%$ do total de cooperativas existentes nos diversos ramos de atividades no Brasil, para o ano de 2014 (OCB, 2015).

A maioria das cooperativas que fazem parte do agronegócio e da distribuição de insumos são cooperativas de produção, consideradas como organizações tradicionais, em geral verticalizadas e diversificadas (CONSOLI; MARINO, 2013).

As cooperativas são verticalizadas, devido a sua função econômica, de integrar verticalmente seus associados na cadeia de comercialização, tanto a montante como a jusante. A característica diferente da integração que ocorre nas cooperativas é que a coordenação é realizada de forma horizontal pelos associados, a fim de realizar a verticalização da cooperativa (SEXTON, 1986).

As cooperativas incorporam estratégias de diversificação, sendo utilizado em geral como um meio de "ajuste competitivo". Muitas delas se destacam no mercado em que atuam, como, por exemplo, a Cooperativa de Cafeicultores e Agropecuaristas de Maringá (COCAMAR) e a Cooperativa Agropecuária Holambra (FERREIRA; BRAGA, 2004).

As principais cooperativas com essas características realizam atividades ligadas às operações de insumos, grãos, processamento e industrialização, sendo que algumas já exportam. Outras, com menor diversificação, atuam como distribuidoras, mas estão focadas em serviços, operação de crédito e atendimento. Essas cooperativas de produção estão concentradas no Sul e Sudeste do Brasil (CONSOLI; MARINO, 2013).

Outras cooperativas que também se concentram no Sul e no Sudeste são aquelas operacionalmente distribuidoras, onde sua principal atividade é a dis- tribuição, são em geral mais agressivas comercialmente. Elas possuem poder de barganha com fornecedores e um amplo portfólio para os produtores (CONSOLI; MARINO, 2013).

A diferença entre cooperativas e empresas consiste no fato de que as cooperativas não possuem uma existência anônima e independente de seus associados, como ocorre nas empresas (sociedade de capital), mas deverão existir como organização econômica intermediária, de modo a prestar serviços aos seus associados, satisfazendo suas necessidades econômicas particulares (BIALOSKORSKI NETO, 2012).

O fato é que cooperativas, enquanto organizações, possuem custos, como aluguel, energia elétrica, manutenção de equipamentos, entre outros. Tais custos são de responsabilidade dos associados que por meio de assembleia ou estatuto definem a cobrança de uma Taxa de Administração, a qual deverá ser paga por cada associado anualmente (CANÇADO et al., 2013).

Ao observar a cooperativa, sob a ótica do cooperado, é possível afirmar que "poderá haver 'lucro' para o membro associado a uma cooperativa e para o seu negócio particular, mas no empreendimento cooperativo em si não há a existência de 'lucro'.'(BIALOSKORSKI NETO, 2012, p. 18).

Dessa forma, a distribuição dos resultados (sobras) de uma cooperativa gera riqueza aos associados. Além dessas, as cooperativas proporcionam aos seus associados diversos serviços, agregando valor à eles, como de assistência técnica, orientação, compra de insumos/produtos, além da comercialização e agregação de valor à produção (BIALOSKORSKI NETO; PINTO, 2012).

Portanto, a sobra, como resultado econômico, não é o único meio que a cooperativa possui de agregar valor ao associado. A prestação de serviços, que também ocorre a partir dos interesses e das necessidades dos associados, agrega valor a esses. Dessa forma, tanto a sobra como a prestação de serviços devem ser parte integrante da avaliação de desempenho de uma cooperativa agropecuária, visto que ambas fazem parte do processo de agregar valor aos produtores rurais associados.

\section{Demonstração do Valor Adicionado}

A informação contábil encontra-se em um processo de transformação de modo a atender às carac- 
terísticas determinantes da evolução organizacional e social. As novas necessidades informacionais da sociedade moderna não são supridas pelo sistema tradicional de informação contábil, que é realizado com foco no desempenho econômico e no aspecto fiscal, não havendo dados de caráter social e ambiental que hoje se fazem necessários à sociedade (KROETZ; COSENZA, 2003).

Isso significa que as organizações atualmente possuem, além do enfoque econômico com o objetivo de produzir riqueza, o enfoque social devido ao fato de serem componentes da sociedade e se interrelacionarem com os demais, empregados, investidores, fornecedores, financiadores, consumidores, Estado e meio ambiente (DE LUCA, 1998).

A partir da necessidade de se prestar informação aos empregados e à sociedade de forma geral surge a ideia de uma demonstração com enfoque social (SANTOS, 2003). Além de visarem ao lucro (enfoque econômico), as organizações devem estar cientes de suas obrigações para com a sociedade de fornecer informações sobre a utilização de recursos humanos, naturais, financeiros, tecnológicos, entre outros pertencentes a essa sociedade (enfoque social) (DE LUCA, 1998).

A ferramenta utilizada para divulgar essas informações com enfoque social é o Balanço Social (BS), o qual evidencia os resultados da organização na área socioeconômica. Alguns gestores enxergam o BS como um meio, simplesmente, de dar transparência aos investimentos sociais que as organizações realizam (DE LUCA, 1998).

Além das informações sociais, o BS pode conter informações de natureza econômica. A Demonstração do Valor Adicionado (DVA) é um componente do BS e que possui essa característica (DE LUCA, 1998; SANTOS, 2003), essa demonstração "deve ser entendida como a forma mais competente criada pela Contabilidade para auxiliar na demonstração da capacidade de geração, bem como de distribuição de riqueza de uma entidade" (SANTOS, 2003, p. 35).

A DVA é um relatório contábil relevante para esclarecer a sociedade sobre a necessidade de existência das organizações (LAUREANO, 2000), de modo que evidencia o valor da riqueza gerada pela entidade e a distribuição para os elementos que contribuíram para sua geração (MANDAL; GOSWAMI, 2008; DE LUCA, 1998).
A autora Dalmácio (2004) conceitua a demonstração, enfatizando que a DVA fornece a "visão abrangente sobre a real capacidade de uma entidade produzir riqueza (no sentido de agregar ou adicionar valor em seu patrimônio) e sobre a forma de como distribuir essa riqueza entre os diversos fatores de produção (trabalho, capital próprio ou de terceiros, governo)" (DALMÁCIO, 2004, p. 91).

A DVA apresenta como resultado o valor adicionado, sendo esta uma informação importante para avaliar o desempenho das empresas cuja operação afeta o bem-estar social e econômico de toda a comunidade. Nela, são reconhecidos os stakeholders que contribuíram no processo de geração de valor da empresa, e é evidenciada na demonstração a parcela distribuída a cada um deles. Uma empresa pode sobreviver sem ter lucro, mas sem geração de valor não sobreviverá (MANDAL; GOSWAMI, 2008).

A riqueza criada nada mais é do que o valor adicionado pela empresa aos insumos, ou seja, o quanto de valor é agregado aos insumos adquiridos em um determinado período (DE LUCA, 1998). O valor adicionado representa a riqueza criada por uma entidade em um determinado período de tempo (DE LUCA, 1998; DALMÁCIO, 2004), ou ainda como concluído por Santos (2003, p. 27) "valor adicionado representa o incremento de valor que se atribui a um bem durante o processo produtivo".

O Pronunciamento Técnico 9 do Comitê de Pronunciamentos Contábeis (CPC) propõem um modelo de DVA a ser seguido pelas entidades. $O$ valor da riqueza criada pela entidade é uma informação da DVA, obtido a partir das Receitas deduzindo insumos adquiridos de terceiros, depreciação, amortização e exaustão.

A informação da riqueza criada pela entidade corresponde ao item 5- Valor adicionado líquido produzido pela entidade (riqueza criada), que corresponde ao valor das Receitas (item 1), menos Insumos Adquiridos de Terceiros (item 2), menos a Depreciação, Amortização e Exaustão (item 4) do modelo proposto pelo CPC. A demonstração evidencia, no item 7 da DVA, o Valor Adicionado total a distribuir, que consiste no resultado do item 5 somado ao Valor Adicionado recebido em transferência (item 6). 


\section{Metodologia}

A pesquisa em questão classifica-se como exploratória e descritiva. A pesquisa exploratória busca um maior conhecimento sobre o tema ou problema de pesquisa em perspectiva (MATTAR, 1999) e a pesquisa descritiva consiste em identificar os fatores que determinam/contribuem para a ocorrência dos fenômenos de modo a aprofundar o conhecimento da realidade (MAGALHÃES; ORQUIZA, 2002).

A partir do estudo dessa pesquisa a finalidade consiste em identificar como as cooperativas agropecuárias geram valor adicionado, buscando evidenciar qual o valor adicionado produzido, assim como identificar a maneira pela qual a cooperativa distribui o valor adicionado aos produtores rurais associados.

O estudo de caso foi realizado na Cooperativa Regional de Cafeicultores em Guaxupé Ltda. (Cooxupé), sendo uma cooperativa agropecuária do sistema agroindustrial do café localizada em Guaxupé, Minas Gerais. A Cooxupé é uma das cooperativas que divulga anualmente a DVA em seus relatórios de gestão, assim como os benefícios proporcionados aos seus cooperados. Desse modo, o objetivo consiste em analisar qual é a agregação de valor e a distribuição de riqueza da cooperativa em questão.

Para tanto, serão utilizados os relatórios de gestão e as demonstrações financeiras publicadas pela cooperativa nos anos de 2012, 2011 e 2010. A cooperativa de cafeicultores atua na revenda de insumos, na prestação de serviços, na armazenagem e comercialização de commodities, na torrefação de café e possui uma loja para venda de seus produtos.

A distribuição do valor adicionado pela cooperativa ao associado é chamado pela cooperativa de cafeicultores de benefícios aos cooperados, que divide-se em benefícios diretos e indiretos.

Os benefícios diretos são aqueles em que a distribuição do valor adicionado pela cooperativa ao associado é recebido diretamente pelo cooperado (em mãos). Na maioria das vezes, são benefícios na forma de numerários, ou seja, em dinheiro. Os benefícios diretos estão divididos em café, insumos, distribuição de numerários e aumento de capital.

Os benefícios indiretos são aqueles em que a distribuição do valor adicionado pela cooperativa ao associado é recebido indiretamente pelo cooperado, ou seja, o cooperado será beneficiado por meio de prestação de serviços ou por meio de subsídios. Os benefícios indiretos estão ligados ao café e consiste em assistência técnica, granelização, subsídio de armazenamento e de transporte.

\subsection{Cooperativa de Cafeicultores}

A Cooxupé possui os relatórios de gestão e as demonstrações financeiras divulgadas em seu próprio site. Ressalta-se que antes da publicação dessas informações pela cooperativa, há uma reunião da Assembleia Geral Ordinária (AGO), normalmente em março do ano seguinte, para tomada de decisões e aprovação dos relatórios e demonstrações.

A cooperativa surgiu, em 1932, com a fundação de uma Cooperativa de Crédito Agrícola, transformada em 1957 em Cooperativa de Cafeicultores. Em 2014, a cooperativa completa 57 anos em atividades de recebimento, processamento e comercialização de café.

A Cooxupé atua na revenda de insumos, na prestação de serviços, na armazenagem e comercialização de commodities, na torrefação de café e possui uma loja para venda de seus produtos. A cooperativa também possui um laboratório de análises químicas que apresenta conceito "A" pela Sociedade Brasileira de Ciência do Solo, onde os cooperados podem utilizar os serviços de análises das plantas e dos solos. Em 2012, foram recebidas 34.090 amostras e foram efetuadas 368.443 determinações.

Foi criada em 2009, integrada à Cooxupé, a Comercial e Exportadora de Café S/A, com o intuito de comercializar, exportar e importar produtos agropecuários em geral, mas principalmente fornecer cafés finos, especiais e certificados, oferecendo lotes únicos ou blends.

Em 2012, a cooperativa possuía 1.904 colaboradores e 9.227 produtores rurais associados, dentre os quais $96,47 \%$ são classificados como mini familiar e pequenos cooperados. A cooperativa recebe café produzido em mais de 200 municípios localizados nas regiões Sul de Minas, Alto Paranaíba (Cerrado Mineiro) e Vale do Rio Pardo, em São Paulo.

A cooperativa lidera a exportação de café verde brasileiro desde 2009, sendo que em 2012 exportou cerca de 2,1 milhões de sacas, sendo este valor $4 \%$ a mais que a média de exportação dos últimos anos. Seu café é exportado principalmente para países 
como Estados Unidos, Alemanha, Bélgica, Suíça, Espanha, Japão, Canadá, entre outros.

\section{Análise dos Resultados}

\subsection{A distribuição de riqueza pela cooperativa de cafeicultores aos cooperados}

A distribuição do valor adicionado pela Cooxupé aos cooperados, é chamada pela cooperativa de benefícios, o qual pode ser considerado como um benefício direto ou indireto.

Serão abordados abaixo quais são esses benefícios, o que significa cada um deles e, serão apresentados os valores e as análises desses benefícios proporcionados pela Cooxupé aos seus cooperados para os anos de 2010 a 2012. Posteriormente, será calculado o valor médio recebido por cooperado, a partir dos benefícios proporcionados a eles pela cooperativa, levando em consideração o número total de cooperados da Cooxupé.

Em relação aos benefícios diretos ligados ao café estão os programas de sustentabilidade, a devolução de crédito de Imposto sobre Circulação de Mercadorias e Serviços (ICMS), devolução do Fundo Especial de Capitalização (FEC) e a concessão de descontos em sacarias.

Os programas de sustentabilidade são investimentos realizados pela cooperativa para que os cooperados possam efetuar melhorias contínuas em suas propriedades, cuja finalidade consiste em promover as melhores práticas de modo a premiar aqueles que se encontram de acordo com os programas de sustentabilidade requeridos pelo mercado nacional e internacional. Sendo esta uma forma de agregar valor, aumentando a qualidade dos produtos de seus cooperados.

A Cooxupé foi credenciada para receber, preparar e comercializar lotes de café com o selo Rainforest Alliance. A cooperativa é uma grande fornecedora mundial de cafés para a Nespresso. Os principais programas oferecidos pela Cooxupé são: Programa AAA da Nespresso, C.A.F.E. Practices da Starbucks, 4C - Código Comum para a Comunidade Cafeeira e UTZ Certified, Programa Nescafé, Programa de qualidade Reinforest.

A devolução de crédito de ICMS consiste na recuperação do imposto incidente nas vendas de café e milho, dos associados, realizadas pela Cooxupé. O governo de Minas Gerais instituiu o crédito de
ICMS presumido, no valor de $1 \%$ nas operações com café cru no Estado e 2,4\% nas operações com milho, para todos os produtores rurais, pessoas físicas.

Em 2010, houve na cooperativa o primeiro crédito de ICMS presumido, totalizando cerca de $\mathrm{R} \$$ 26,3 milhões, que foram contemplados por 8.812 cooperados (que comercializavam café e milho) entre o período de dezembro de 2009 e setembro de 2010. O benefício direto de repasse do valor do ICMS recuperado aos cooperados consiste na distribuição do valor adicionado.

O Fundo Especial de Capitalização (FEC) foi criado e aprovado pela AGO da Cooxupé em 1998, durante o período de vigência do Programa de Revitalização de Cooperativas de Produção Agropecuária (RECOOP), pela absorção da sobra líquida apurada no fim de cada exercício social.

Em 2007, foi decidido em assembleia que a partir do próximo ano não seria mais obrigatória a constituição da FEC. O que ocorre atualmente é a devolução da FEC, sendo esta considerada um benefício direto aos cooperados da Cooxupé.

Além dos benefícios diretos ligados ao café já descritos, a cooperativa distribui riqueza aos associados por meio de devolução de capital e na concessão de descontos em sacarias.

Em relação aos benefícios diretos ligados aos insumos, a cooperativa proporciona a revenda de insumos aos associados, bônus e descontos nas campanhas de vendas. Momento em que os associados compram defensivos e fertilizantes agrícolas, por exemplo, a valores menores do que encontrariam no mercado.

Como já mencionado, os benefícios indiretos proporcionados pela Cooxupé aos associados são: assistência técnica, granelização, subsídio de armazenamento e de transporte.

A cooperativa presta serviços de assistência técnica aos cooperados gratuitamente, por meio de eventos coletivos, orientação direta ao produtor com a possibilidade de visitas à propriedade quando necessário. No ano de 2012, a cooperativa possuía 160 profissionais atuando no atendimento técnico gratuito aos produtores rurais associados, totalizando 69.585 atendimentos. A prestação de serviços incorre em custos à cooperativa, mas agrega valor ao associado.

Com os serviços prestados pela cooperativa, o associado adquire maiores técnicas, informações e 
conhecimento que podem vir a auxiliar no trabalho realizado em suas fazendas. O resultado desse benefício indireto consiste, muitas vezes, em menores custos e desperdícios e em maior qualidade dos produtos pertencentes aos associados.

Quadro 1 - Benefícios diretos e indiretos proporcionados pela cooperativa de cafeicultores aos seus cooperados entre 2010-2012

\begin{tabular}{|c|c|c|c|c|c|c|c|c|c|}
\hline \multirow[b]{2}{*}{ Benefícios diretos } & \multicolumn{3}{|c|}{2012} & \multicolumn{3}{|c|}{2011} & \multicolumn{3}{|c|}{2010} \\
\hline & valor em R\$ & $\mathrm{AV}(\%)$ & $\mathrm{AH}(\%)$ & valor em R\$ & $\mathrm{AV}(\%)$ & $\mathrm{AH}(\%)$ & valor em $\mathrm{R} \$$ & $\mathrm{AV}(\%)$ & $\mathrm{AH}(\%)$ \\
\hline Café & 20.965 .938 & 27,82 & $-55,46$ & 16.383.828 & 22,31 & $-65,19$ & 47.070.528 & 61,33 & 100,00 \\
\hline Programa de qualidade Nespresso & 6.961 .850 & 9,24 & 10,03 & 5.182 .289 & 7,06 & $-18,09$ & 6.327 .178 & 8,24 & 100,00 \\
\hline Programa de qualidade Jornada da Excelência e UTZ & 126.828 & 0,17 & $-30,95$ & 541.521 & 0,74 & 194,83 & 183.670 & 0,24 & 100,00 \\
\hline Programa Nescafé & 706.015 & 0,94 & & & & & & & \\
\hline Programa de qualidade Reinforest & 338.635 & 0,45 & 0,00 & 134.260 & 0,18 & 0,00 & & & \\
\hline Devolução de crédito de ICMS presumido & 7.739 .911 & 10,27 & $-70,60$ & 2.646 .839 & 3,60 & $-89,95$ & 26.327 .226 & 34,30 & 100,00 \\
\hline Devolução do fundo especial de capitalização - FEC & 962.597 & 1,28 & $-65,49$ & 753.536 & 1,03 & $-72,99$ & 2.789 .640 & 3,63 & 100,00 \\
\hline Devolução de capital & 4.130 .102 & 5,48 & $-23,46$ & 2.743 .141 & 3,73 & $-49,17$ & 5.396 .215 & 7,03 & 100,00 \\
\hline Programa de qualidade $4 \mathrm{C}$ & & & & 470.752 & 0,64 & 29,46 & 363.619 & 0,47 & 100,00 \\
\hline Concessão de desconto de sacaria & & & & 3.911 .490 & 5,33 & $-31,17$ & 5.682 .981 & 7,40 & 100,00 \\
\hline Insumos & 8.909 .520 & 11,82 & $\mathbf{7 0 , 8 1}$ & 7.238.979 & 9,86 & 38,79 & 5.215 .925 & 6,80 & 100,00 \\
\hline Bônus e descontos das campanhas de vendas & 8.909 .520 & 11,82 & 70,81 & 7.238.979 & 9,86 & 38,79 & 5.215 .925 & 6,80 & 100,00 \\
\hline Subtotal dos benefícios diretos do café e dos insumos & 29.875.458 & 39,65 & $-42,86$ & 23.622.807 & 32,16 & $-54,82$ & 52.286 .453 & 68,12 & 100,00 \\
\hline Distribuição de numerários ( $10 \%$ sobre as sobras) & 4.232.073 & 5,62 & & 9.388 .930 & 12,78 & & & & 100,00 \\
\hline Aumento do capital (10\% sobre as sobras) & 4.232.073 & 5,62 & $-39,86$ & 9.388 .930 & 12,78 & 33,42 & 7.037.099 & 9,17 & 100,00 \\
\hline Rec do conselho de adm (50\% à disposição da AGO) & & & & 9.388.931 & & & & & \\
\hline $\begin{array}{l}\text { Total de Benefícios Diretos } \\
\text { Benefícios indiretos }\end{array}$ & $\begin{array}{r}\mathbf{3 8 . 3 3 9 . 6 0 4} \\
\text { valor em } R \$\end{array}$ & 50,88 & $-35,37$ & $\begin{array}{c}\mathbf{5 1 . 7 8 9 . 5 9 8} \\
\text { valor em } \mathrm{R} \$\end{array}$ & 70,51 & $-12,70$ & $\begin{array}{r}\mathbf{5 9 . 3 2 3 . 5 5 2} \\
\text { valor em } \mathrm{R} \$\end{array}$ & 77,29 & 100,00 \\
\hline Café & & & & & & & & & \\
\hline Assistência técnica (atendimentos) & 8.491 .055 & 11,27 & 54,72 & 8.330 .772 & 11,34 & 51,80 & 5.487 .846 & 7,15 & 100,00 \\
\hline Subsídio de armazenagem & 7.394 .476 & 9,81 & $-16,13$ & 5.848 .946 & 7,96 & $-33,66$ & 8.816 .720 & 11,49 & 100,00 \\
\hline Subsídio de transporte & 4.206 .485 & 5,58 & 34,58 & 2.276 .706 & 3,10 & $-27,16$ & 3.125 .593 & 4,07 & 100,00 \\
\hline Granelização & 16.922 .387 & 22,46 & & 5.204 .800 & 7,09 & & & & \\
\hline Total de Benefícios Indiretos & 37.014 .403 & 49,12 & 112,36 & 21.661.224 & 29,49 & 24,27 & 17.430.159 & 22,71 & 100,00 \\
\hline Total Geral de Benefícios Diretos e Indiretos & 75.354.007 & 100,00 & $-1,82$ & 73.450 .822 & 100,00 & $-4,30$ & 76.753.711 & 100,00 & 100,00 \\
\hline Crédito de ICMS presumido (devolução AGO 2012) & & & & $\begin{array}{r}8.533 .957 \\
\mathbf{8 1 . 9 8 4 . 7 7 9}\end{array}$ & & & & & \\
\hline
\end{tabular}

Fonte: Relatório de Gestão e Demonstrações Financeiras da cooperativa de cafeicultores em 2012, 2011 e 2010.

Em 2011, a Cooxupé iniciou um trabalho de armazenamento do café a granel e não mais em sacaria. $\mathrm{O}$ café passou a ser acondicionado em bags que possuem chip, onde está a identidade do produtor, permitindo a rastreabilidade até a venda do café. Com a eliminação da sacaria, a logística de armazenamento na cooperativa melhorou, além de o associado economizar com mão de obra e ganhar velocidade no envio do café para a cooperativa. Fato que melhora a qualidade do café e reduz os custos com frete.

Em 2011, houve uma economia na cooperativa de aproximadamente $\mathrm{R} \$ 5,2$ milhões e, em 2012, a economia foi $225 \%$ maior, cerca de $\mathrm{R} \$ 16,9 \mathrm{mi}-$ lhões, considerados pela cooperativa como benefícios indiretos proporcionados aos associados. A redução de custos pela cooperativa proporciona, consequentemente, maiores resultados.

A Cooxupé subsidia o armazenamento da produção do café de seus cooperados e, também, subsidia o transporte de cargas desse café para a cooperativa, sendo esses benefícios considerados indiretos, de modo que agregam valor ao cooperado.

O Quadro 1 evidencia os benefícios diretos e indiretos que a cooperativa proporcionou aos produtores rurais associados a ela em 2010, 2011 e 2012.Como evidenciado anteriormente, a Cooxupé agrega valor e distribui riqueza aos seus associados por meio dos benefícios diretos (ligados ao café, insumos, distribuição de numerários e aumento de capital) e benefícios indiretos (assistência técnica, granelização, subsídio de armazenamento e de transporte). 
Praticamente todos os cooperados estão inscritos em pelo menos um dos programas de sustentabilidade ligados ao café (benefício direto). Em 2012, 4.703 cooperados tiveram sua renda aumentada por meio de premiações que totalizaram $\mathrm{R} \$$ 8.133.328, o que corresponde a $10 \%$ do total geral de benefícios e um valor médio de aproximadamente $\mathrm{R} \$$ 1.729 para cada cooperado premiado.

O Programa de Qualidade Nespresso proporciona aos cooperados benefícios no valor de $\mathrm{R} \$$ 6.961 .850 , aproximadamente $86 \%$ em relação ao total de programas de sustentabilidade. Os programas são importantes tanto para a cooperativa como aos cooperados, pois fazem com que a Cooxupé cumpra com as exigências requeridas no mercado nacional e internacional, aumentando a qualidade do café produzido pelos produtores rurais associados e, consequentemente, trazendo melhores resultados na venda desse café.

As devoluções de crédito do ICMS presumido, do FEC e de capital totalizam R $\$ 12.832 .610$, o que corresponde a $18 \%$ em relação ao total geral de benefícios. Em 2012, a recuperação de ICMS presumido pela cooperativa e sua distribuição aos cooperados foi de aproximadamente $\mathrm{R} \$ 7,7$ milhões.

Esse valor é repassado aos cooperados quando da venda de suas commodities, sendo inserido nas notas fiscais do café comercializado. O número de cooperados que receberam a devolução do imposto totalizaram 8.018, de modo que o valor médio recebido por cooperado beneficiado foi de aproximadamente R\$ 965.

Em 2012, a devolução do FEC aos cooperados foi de R\$962.597, valor este recebido por 399 cooperados, o que evidencia um valor médio recebido por cooperado beneficiado de $\mathrm{R} \$ 2.412,50$. Houve também, no mesmo ano, devolução de capital a 489 cooperados, no valor de $\mathrm{R} \$ 4.130 .102$, sendo recebido um valor médio por cooperado beneficiado de aproximadamente $\mathrm{R} \$ 8.446$.

As devoluções descritas (de crédito de ICMS presumido, do FEC e de capital) distribuem riqueza aos cooperados, sendo consideradas como benefícios diretos proporcionados pela Cooxupé aos produtores rurais associados.

Os benefícios diretos ligados aos insumos ocorrem por meio de bônus e descontos das campanhas de vendas. Em 2012, foram proporcionados pela cooperativa aos associados bônus e descontos no valor de $\mathrm{R} \$ 8.909 .520$, os quais foram recebidos por 8.865 cooperados. Dessa forma, tem-se um valor médio de $\mathrm{R} \$ 1.005$ de bônus e descontos na venda de insumos por cooperado beneficiado.

Houve uma reforma no Estatuto Social da Cooxupé, que era o mesmo desde 1987. Em agosto de 2011, foi convocada uma assembleia de caráter extraordinário, com a finalidade de analisar o Estatuto Social que precisava ser atualizado. Nessa assembleia, entre outras decisões, ficou estipulado que $10 \%$ das sobras líquidas de cada exercício social seriam distribuídas aos associados, sem a necessidade de passar por votação em assembleia.

Em 2012, a distribuição de numerários aos cooperados foi de $\mathrm{R} \$ 4.232 .073$ que corresponde a $5,62 \%$ do total geral de benefícios. A distribuição de numerários pode ser uma mudança na estratégia da cooperativa no modo com que ela distribui o valor adicionado aos cooperados. É possível que o cooperado tenha uma percepção de que a cooperativa agrega maior valor adicionado a eles, quando do retorno financeiro do que na prestação de serviços gratuitos, por exemplo.

O Capital Social da Cooxupé é representado por quotas no valor nominal de $\mathrm{R} \$ 1,00$. Consta em Estatuto um aumento de capital, ao fim de cada exercício social, de $10 \%$ em relação às sobras líquidas da cooperativa. Em 2012, houve um aumento de capital no valor de $\mathrm{R} \$ 4.232 .073$, o que corresponde a 5,62\% do total geral de benefícios. O aumento de capital é um benefício do cooperado, sendo também, um meio de reinvestir na cooperativa que trará benefícios futuros.

Em relação aos benefícios indiretos, como já mencionado, a prestação de serviços por meio de assistência técnica aos cooperados é oferecida gratuitamente pela cooperativa. Em 2012, foram investidos R\$ 8.491.055 para a realização de 69.585 atendimentos, evidenciando um custo médio por atendimento de $\mathrm{R} \$ 122$.

O valor total investido em assistência técnica corresponde a $11,27 \%$ do total geral dos benefícios. A prestação desse serviço agrega valor aos cooperados que, com as corretas instruções técnicas e as devidas informações, podem adicionar qualidade na produção do café.

O cooperado possui a opção de entregar na Cooxupé o café a granel, eliminando o saco de juta. Em 2012, a cooperativa investiu $R \$ 16.922 .387$ na granelização (benefício indireto) que beneficiou 6.982 cooperados, este benefício corresponde a 
$22,46 \%$ do total geral de benefícios. O custo médio de granelização por cooperado beneficiado foi de $\mathrm{R}$ \$ 2.424. A implantação da granelização na Cooxupé facilita a logística para o cooperado da entrega do café, além da redução de custos, como já mencionado anteriormente.

Outro benefício indireto proporcionado pela Cooxupé aos seus cooperados é o subsídio de armazenamento que, em 2012, totalizou $\mathrm{R} \$ 7.394 .476 \mathrm{e}$ beneficiou 8.940 cooperados. O que evidencia um subsídio de armazenamento médio por cooperado beneficiado de $\mathrm{R} \$ 827$.

A Cooxupé também proporciona ao cooperado um subsídio de transporte que, em 2012, totalizou $\mathrm{R} \$$ 4.206.485, beneficiando 2.727 cooperados. Dessa forma, o subsídio de transporte médio por cooperado beneficiado é de $\mathrm{R} \$ 1.543$. Ambos os subsídios agregam valor aos cooperados, pois, caso a cooperativa não subsidiasse, o produtor rural teria de pagar para armazenar e transportar as cargas de café.

Ao analisar o ano de 2012, por meio da análise vertical, observa-se que aproximadamente $50 \%$ do total geral de benefícios corresponde aos benefícios diretos e os outros $50 \%$, aos benefícios indiretos. Os benefícios diretos proporcionados aos cooperados, em 2012, foram de $\mathrm{R} \$ 38.339 .604$, distribuídos por meio de prêmios dos programas de sustentabilidade, devoluções em dinheiro, bônus e descontos nas vendas de insumos, distribuição de numerários e aumento de capital.

Em relação aos benefícios indiretos, ressalta-se que ocorrem na forma de prestação de serviços aos cooperados. Em 2012, o total de benefícios indiretos foi de $\mathrm{R} \$ 37.014 .403$, o que representa os custos que a cooperativa subsidiou ao proporcionar serviços gratuitos aos cooperados.

Ao realizar uma análise horizontal, tem-se como objetivo observar a tendência de uma determinada informação no decorrer dos anos. Ressalta-se que a limitação neste trabalho consiste na pequena quantidade de anos analisados (2010, 2011 e 2012). Antes de realizar uma análise horizontal é relevante entender o funcionamento do segmento do café, pois existem fatores exógenos à cooperativa e ao produtor rural que afetam diretamente os resultados desse anualmente.

Deve-se levar em consideração, dentro do segmento, o comportamento cíclico da produção do café, o preço e a taxa de câmbio. Esses três fatores alteram o comportamento anual do café e, consequentemente, os resultados nas entidades que possuem como atividade principal a compra, industrialização e/ou comercialização desse.

A produção de café possui um comportamento cíclico bienal, caracterizado pela alternância entre aumentos e quedas na produção. Em um ano, ocorre uma colheita abundante e, no próximo ano, ocorre uma colheita menor. Esse comportamento cíclico pode ainda sofrer variações por fatores climáticos, como secas, chuvas excessivas e geadas (Organização Internacional do Café - OIC, 2010).

Nos resultados financeiros do ano de 2010, está relacionada a safra de 2009/2010, considerada baixa na produção do café. Consequentemente, no próximo ano (2010), a safra 2010/2011 é considerada alta na produção, trazendo maiores resultados financeiros no ano de 2011. Dessa forma, para o ano de 2012, a safra 2011/2012 é considerada baixa, evidenciando resultados

financeiros menores nesse ano e assim por diante.

O impacto do ciclo bienal do Brasil reflete na formação dos preços a nível mundial, uma vez que o país possui mais de $30 \%$ de participação na produção mundial. A média do preço de exportação do café valorizou, em 2011, 56,71\% em relação ao ano anterior (OIC, 2010).

Em relação aos valores médios do agronegócio de 2011 e de 2010 , houve alta de $26,7 \%$ nos preços externos em dólares. Já em 2012, os preços médios de exportação em dólar recuaram 2,9\% em relação ao ano anterior (ESALQ/USP, 2013).

A taxa de câmbio efetiva real do agronegócio apresentou valorização em 2010 e se apresentou estável até setembro de 2011, quando foi observado um aumento da aversão ao risco devido à crise na Europa, e o Banco Central do Brasil anunciou mudanças na política de juros.

$\mathrm{Na}$ comparação das médias anuais (2010 e 2011), houve valorização cambial de 19,2\%. Em 2012, houve uma desvalorização de $2 \%$ da taxa de câmbio efetiva real do agronegócio. Apesar de o câmbio ter desvalorizado no período, o faturamento em reais, por sua vez, cresceu $6 \%$, devido ao aumento do volume exportado que foi de $8,67 \%$ (ESALQ/USP, 2013).

Em 2010, o preço médio pago pela saca do café aos cooperados da Cooxupé foi de $\mathrm{R} \$ 302,11$, possuindo um aumento em relação ao ano anterior de 
$15,21 \%$. O preço médio pago pela saca do café aos cooperados da Cooxupé, em 2011, foi de $\mathrm{R} \$$ 477,86, um aumento de aproximadamente $58 \%$ em relação ao preço médio pago pela saca no ano de 2010.

O ano de 2011, é considerado de safra baixa (safra 2011/2012), mas o reflexo financeiro do ano veio a partir da safra anterior (safra 2010/2011), sendo que a Cooxupé trabalhou com o estoque que possuía.

Portanto, o preço alto da saca do café e um estoque significativo da cooperativa contribuíram para os resultados em 2011.

Em 2012, o preço médio pago pela saca de café ao cooperado foi de $\mathrm{R} \$ 384,45$, representando uma queda no preço médio pago em relação ao ano anterior de aproximadamente 20\%. Mas, levando em consideração o ciclo bienal, ao comparar o ano de 2012 com o ano de 2010, ambos considerados resultados de uma safra de baixa na produção de café, houve um aumento pago no valor médio do café aos cooperados da Cooxupé de aproximadamente $27 \%$.

Retornando ao Quadro 1, por meio da análise horizontal, observa-se que o total geral dos benefícios nos anos analisados foi estável, com uma pequena variação negativa do ano de 2012 em relação ao ano de 2010 de $1,82 \%$. Houve três contas com aumentos significativos, de 2012 em relação a 2010, o primeiro é o benefício direto de bônus e descontos das campanhas de vendas dos insumos que, em 2012, totalizou R\$ 8.909.520 e, em 2010, era de $\mathrm{R} \$$ 5.215.925, representando um aumento de 70,81\%.

$\mathrm{O}$ segundo e o terceiro aumentos significativos pertencem aos benefícios indiretos. O segundo é a prestação de serviços na forma de assistência técnica que, em 2012, totalizou um custo de R\$ 8.491.055, enquanto, em 2010, era de $\mathrm{R} \$$ 5.487.846, obtendo um aumento dentro de dois anos de $54,72 \%$. E o terceiro é o subsídio de transporte que, em 2012, foi de $\mathrm{R} \$ 4.206 .485$ e, em 2012, era de $\mathrm{R} \$ 3.125 .593$, correspondente a um aumento de $34,58 \%$.
Existem, também, diminuições significativas de alguns benefícios, os quais estão relacionados aos benefícios diretos ligados ao café e ao aumento de capital. Os benefícios diretos ligados ao café totalizaram, em 2012, R\$ 20.965.938, enquanto, em 2010 , foram distribuídos $\mathrm{R} \$ 47.070 .528$ de benefícios diretos relacionados ao café aos cooperados. Houve uma diminuição significativa em 2012 em relação a 2010, correspondente a 55,46\%.

Isso se deve principalmente pela devolução de crédito do ICMS presumido, sendo que, em 2012, foram devolvidos aos cooperados $\mathrm{R} \$ 7.739 .911 \mathrm{e}$, em 2010, R\$ 26.327.226, evidenciando uma diminuição de 70,60\%; pela devolução do FEC, que em 2012, totalizou R\$ 962.597 e, em 2010, era de R\$ 2.789.640, representando uma diminuição no valor devolvido do FEC em 65,49\%.

E, também, o benefício direto de aumento de capital que, em 2012, totalizou $\mathrm{R} \$ 4$ 4232.073, em 2011, era de $\mathrm{R} \$ 7.037 .099$, o que corresponde a uma diminuição de $39,86 \%$. O aumento de capital está relacionado diretamente com as sobras líquidas do exercício, sendo que são destinados ao aumento de capital $10 \%$ das sobras líquidas da cooperativa anualmente.

É válido ressaltar que apesar de não aparecer nenhum aumento de capital na tabela de benefícios do Relatório de Gestão da Cooxupé do ano de 2010, ao verificar as destinações estatutárias e legais, observa-se um aumento de capital no período de $\mathrm{R} \$$ 7.037.099,

De acordo com o estatuto social da Cooxupé e a Lei n. 5.764/71, a sobra líquida do exercício, ajustada pela realização da Reserva de Reavaliação e da Reserva de Assistência Técnica, Educacional e Social (RATES), terá as destinações assim como estão representadas no Quadro 2.

Ressalta-se que a RATES é composta pelos resultados das operações com não cooperados, ou seja, o lucro líquido do período é destinado à reserva. 
Quadro 2 - Resultados dos períodos e suas destinações estatutárias e legais dos anos.de 2012, 2011 e 2010

\begin{tabular}{|l|r|r|r|}
\hline \multicolumn{1}{|c|}{ Destinações Estatutárias e Legais: } & \multicolumn{1}{c|}{2012} & \multicolumn{1}{c|}{2011} & \multicolumn{1}{c|}{2010} \\
\hline Sobra líquida do exercício & 18.918 .003 & 140.523 .047 & 78.097 .304 \\
Ajuste de exercícios anteriores & & & -3.527 .440 \\
Realização da RATES & 10.831 .636 & 10.154 .851 & 8.687 .796 \\
Realização da Reserva de reavaliação & 4.608 .012 & 4.447 .157 & 4.373 .305 \\
Lucro líquido antes das destinações & $\mathbf{3 4 . 3 5 7 . 6 5 1}$ & $\mathbf{1 5 5 . 1 2 5 . 0 5 5}$ & $\mathbf{8 7 . 6 3 0 . 9 6 5}$ \\
Destinações diretas & & & \\
RATES (Lucro líquido com não cooperados) & -1.606 .767 & -8.598 .156 & -10.535 .096 \\
Reserva de desenvolvimentos & 9.569 .848 & -52.637 .594 & -53.638 .874 \\
Destinações conforme disposições estatutárias & $\mathbf{4 2 . 3 2 0 . 7 3 2}$ & $\mathbf{9 3 . 8 8 9 . 3 0 5}$ & $\mathbf{2 3 . 4 5 6 . 9 9 5}$ \\
Reserva Legal (30\%) & -12.696 .220 & $-28.166 .791,00$ & -7.037 .099 \\
RATES (15\%) & -6.348 .110 & -14.083 .396 & -2.345 .700 \\
Reserva de desenvolvimento (15\%) & -6.348 .110 & -14.083 .396 & \\
Capital Social (10\%) & -4.232 .073 & -9.388 .930 & -7.037 .099 \\
Distribuição aos cooperados (10\%) & -4.232 .073 & -9.388 .930 & \\
Sobras à disposição da Assembleia Geral & $\mathbf{8 . 4 6 4 . 1 4 6}$ & $\mathbf{1 8 . 7 7 7 . 8 6 2}$ & $\mathbf{7 . 0 3 7 . 0 9 7}$ \\
Destinação (decisão da Assembleia): & mar/14 & mar/12 & mar/11 \\
Reserva Legal & & -9.388 .931 & \\
Capital Social & & -9.388 .931 & \\
RATES & & & -7.037 .097 \\
\hline
\end{tabular}

Fonte: Relatório de Gestão e Demonstrações Financeiras da Cooxupé em 2012, 2011 e 2010.

Como se pode observar, a sobra líquida de 2012 foi de $\mathrm{R} \$ 18,9$ milhões, resultado de aproximadamente $86 \%$ inferior ao ano anterior $(\mathrm{R} \$ 140,5 \mathrm{mi}-$ lhões), isso se deve principalmente pela queda no preço do café no mercado internacional.

O lucro líquido, antes das destinações, consiste na soma da sobra líquida do exercício, do ajuste de exercícios anteriores, da realização da RATES e da realização da reserva de reavaliação. Posteriormente, parte desses valores é destinada diretamente à conta RATES e à reserva de desenvolvimentos.

A diferença entre o lucro líquido antes das destinações e as destinações diretas é destinada conforme disposição estatutária, sendo esta a base de cálculo para a distribuição mencionada a seguir.

É destinado à reserva legal 30\% desse valor, cuja finalidade consiste em reparar perdas e atender ao desenvolvimento de suas atividades. Ao RATES, cujo objetivo está na prestação de assistência aos cooperados, destina-se $15 \%$. Sendo esta a mesma porcentagem destinada à reserva de desenvolvimento, a qual visa a investimentos em infraestrutura, novas tecnologias e investimento em capital de giro.

Reservam-se ao aumento de capital 10\% das destinações, conforme disposições estatutárias. Aos cooperados, destina-se também uma porcentagem de $10 \%$, cujo numerário será distribuído aos cooperados. O restante cabe à Assembleia Geral Ordinária deliberar sobre sua destinação, fato que acontece normalmente na Cooxupé em março do ano seguinte.

A partir das informações dos Relatórios de Gestão, foi calculado o valor médio recebido por cooperado, a partir dos benefícios proporcionados a eles pela cooperativa, levando em consideração o número total de cooperados da Cooxupé, como segue: 
Quadro 3 - Valor médio recebido por cooperado em relação aos benefícios proporcionados pela cooperativa de cafeicultores em 2012, 2011 e 2010

\begin{tabular}{|c|c|c|c|c|c|c|c|c|c|c|c|c|}
\hline & 2012 & $\begin{array}{l}\text { Vlr médio } \\
\text { por coop. }\end{array}$ & $\mathrm{AV}(\%)$ & $\mathrm{AH}(\%)$ & 2011 & $\begin{array}{l}\text { Vlr médio } \\
\text { por coop. }\end{array}$ & $\operatorname{AV}(\%)$ & $\mathrm{AH}(\%)$ & 2010 & $\begin{array}{l}\text { Vlr médio } \\
\text { por coop. }\end{array}$ & $\operatorname{AV}(\%)$ & $\mathrm{AH}(\%)$ \\
\hline $\mathrm{N}^{\circ}$ total de cooperados & 9.227 & & & $-22,30$ & 10.661 & & & $-10,22$ & 11.875 & & & 100,00 \\
\hline Benefícios diretos & 38.339 .604 & $4.155,15$ & 50,88 & $-16,82$ & 42.400 .667 & $3.977,18$ & 66,19 & $-20,39$ & 59.323 .552 & $4.995,67$ & 77,29 & 100,00 \\
\hline Café + insumos & 29.875 .458 & $3.237,83$ & 39,65 & $-26,46$ & 23.622 .807 & $2.215,82$ & 36,87 & $-49,68$ & 52.286 .453 & $4.403,07$ & 68,12 & 100,00 \\
\hline Distribuição de numerários & 4.232 .073 & 458,66 & 5,62 & & 9.388 .930 & 880,68 & 14,66 & & 0 & 0,00 & 0,00 & 100,00 \\
\hline Aumento de capital & 4.232 .073 & 458,66 & 5,62 & $-22,60$ & 9.388 .930 & 880,68 & 14,66 & 48,61 & 7.037.099 & 592,60 & 9,17 & 100,00 \\
\hline Benefícios indiretos & 37.014 .403 & $4.011,53$ & 49,12 & 173,30 & 21.661 .224 & $2.031,82$ & 33,81 & 38,43 & 17.430 .159 & $1.467,80$ & 22,71 & 100,00 \\
\hline Valor total de benefícios & 75.354.007 & $8.166,69$ & 100,00 & 26,35 & 64.061.891 & $6.008,99$ & 100,00 & $-7,03$ & 76.753.711 & $6.463,47$ & 100,00 & 100,00 \\
\hline
\end{tabular}

Fonte: Elaborado pela autora a partir das informações dos Relatórios de Gestão da cooperativa de cafeicultores em 2012,2011 e 2010.

A Cooxupé, a partir de 2011, passou a destinar parte das sobras à distribuição de numerários aos cooperados. Fato este que evidencia uma possível mudança de estratégia na maneira como a cooperativa distribui a riqueza gerada aos cooperados.

Observa-se que o número de produtor rural associado à Cooxupé, ao analisar 2012 em relação a 2011, caiu 22,30\%. Em 2012, a cooperativa possuía 9.227 associados e, em 2010, 11.875 associados. Mas o valor total de benefícios distribuídos não caiu na mesma proporção, houve uma redução de $1,82 \%$. Em 2012, a cooperativa distribuiu $\mathrm{R} \$ 75.354 .007$ em benefícios aos cooperados e, em 2011, distribuiu R\$ 76.753.711.

Fato esse que proporcionou um maior valor médio total de benefícios distribuídos por cooperado, analisando 2012 em relação a 2011. O valor médio total recebido por cooperado, em 2012, foi de $\mathrm{R} \$$ $8.167,69$, sendo que, em 2010, foi de $\mathrm{R} \$ 6.463,47$, o que corresponde a um aumento de $26,35 \%$ no valor dos benefícios distribuídos.

Já em 2011, a queda no valor total de benefícios foi maior do que a redução de associados. $\mathrm{O}$ que fez com que o valor médio total recebido por cooperado caísse, em 2011, já que foram distribuídos 6.008,99, enquanto, em 2012, foram $\mathrm{R} \$ 6.463,47$, resultando em uma queda do valor médio total recebido por cooperado, em relação ao ano anterior, de 7,03\%.
Ao analisar o valor total dos benefícios diretos e dos indiretos, observa-se que a maneira pela qual a cooperativa distribui a riqueza gerada aos cooperados vem mudando. Houve uma redução na média dos benefícios diretos recebidos por cooperado de 2012 em relação a 2010, em 16,82\%. Em contrapartida ocorreu um aumento expressivo na média de benefícios indiretos recebidos por cooperado de 2012 em relação a 2010, de 173,30\%.

O valor médio dos benefícios indiretos proporcionados a cada cooperado, em 2012, totalizou R\$ $4.011,53$ e, em 2010, R\$ 1.467,80. Em 2012, os benefícios indiretos representaram 49,12\% do valor médio total recebido por cooperado, sendo que em 2010 representava $22,71 \%$ do valor médio total recebido por cooperado.

\subsection{Demonstração do Valor Adicionado na coo- perativa de cafeicultores}

A partir das informações expostas na Demonstração do Valor Adicionado, é possível o cálculo de alguns índices que auxiliam na análise da distribuição de riqueza de uma entidade. Para tanto, foram utilizados os índices sugeridos pelos autores Laureano (2000) e Dalmácio (2004). Assim, os índices foram aplicados nas informações contidas na demonstração da Cooxupé, para os anos de 2012, 2011 e 2010. 
Quadro 4 - Índices gerados a partir das informações contidas na Demonstração do Valor Adicionado da cooperativa de cafeicultores em 2012, 2011 e 2010

\begin{tabular}{|c|c|c|c|}
\hline Índices & 2012 & 2011 & 2010 \\
\hline \multicolumn{4}{|l|}{ Participações no valor adicionado total dis tribuido } \\
\hline Participação de colaboradores no VA $(\%)$ & 35,59 & 23,49 & 26,07 \\
\hline Participação de governos no VA (\%) & 10,17 & 6,81 & 14,86 \\
\hline Participação de terceiros no VA (\%) & 26,26 & 29,89 & 29,85 \\
\hline Participação das sobras no VA $(\%)$ & 7,97 & 39,81 & 29,22 \\
\hline Grau de dis tribuição de numerários do valor adicionado (\%) & 1,78 & 2,66 & \\
\hline Grau de retenção do valor adicionado (\%) & 1,78 & 2,66 & 2,63 \\
\hline Grau de capacidade de produzir riqueza $(\%)$ & 69,16 & 81,65 & 75,88 \\
\hline Grau de riqueza produzida em transferência $(\%)$ & 30,84 & 18,35 & 24,12 \\
\hline Grau de contribuição na formação da riqueza de outras entidades $(\%)$ & 92,88 & 90,86 & 89,56 \\
\hline Grau de contribuição dos ativos na geração de riqueza $(\%)$ & 6,98 & 12,64 & 10,78 \\
\hline Grau de contribuição do patrimônio líquido na geração de riqueza (\%) & 47,47 & 71,54 & 72,75 \\
\hline
\end{tabular}

Fonte: Elaborado pela autora a partir das informações dos Relatórios de Gestão da cooperativa de cafeicultores em 2012,2011 e 2010.

Os índices referentes às participações no valor adicionado total distribuído representam o percentual de cada participação no total do valor adicionado a distribuir pela entidade, ou seja, representam os percentuais de distribuição de riqueza (DALMÁCIO, 2004).

Dessa forma, ao analisar o ano de 2012, observase na DVA que aos colaboradores foi distribuído um valor total de $\mathrm{R} \$ 84.447 .885$ que inclui remuneração direta, benefícios e FGTS. O índice de participação de colaboradores no valor adicionado da cooperativa foi de $35,59 \%$, ou seja, valor esse da riqueza gerada pela cooperativa e distribuída aos funcionários da Cooxupé.

A DVA, em 2012, evidencia distribuição do valor adicionado ao governo, no valor de $\mathrm{R} \$$ 24.127.571. O índice de participação do governo, no valor adicionado da cooperativa, foi de $10,17 \%$, isso representa que aproximadamente $10 \%$ da riqueza gerada pela cooperativa foi direcionada para o pagamento de impostos.

Em 2012, por meio da DVA, evidencia-se a distribuição do valor adicionado da cooperativa para terceiros, envolvendo juros e aluguéis, no valor de R\$ 109.767.196. O índice de participação de terceiros no valor adicionado representou $26,26 \%$, evidenciando a parte da riqueza gerada pela cooperativa que foi distribuída entre terceiros.

Por fim, as sobras líquidas são apresentadas na DVA do ano de 2012, no valor de R $\$ 18.918 .003$. O índice da participação das sobras no valor adiciona- do da cooperativa representou $7,97 \%$ em relação ao valor adicionado total distribuído pela cooperativa.

É importante mencionar que o índice participação das sobras no valor adicionado utiliza as sobras provenientes do resultado da Demonstração do Resultado do Exercício, de modo que o montante das sobras da cooperativa é ajustado e distribuído de acordo com destinações estatutárias e legais.

Sugere-se o índice grau de distribuição de numerários do valor adicionado, onde pode-se observar o montante das sobras que foram distribuídos aos cooperados. Em 2012, foram distribuídos $\mathrm{R} \$$ 4.272.073 aos cooperados, evidencia que $1,78 \%$ do valor adicionado total distribuído pela cooperativa encontra-se, em numerários, com os cooperados.

O grau de retenção do valor adicionado indica o percentual de riqueza criada que será agregado ao capital próprio (LAUREANO, 2000; DALMÁCIO, 2004). Em 2012, houve um aumento de capital na Cooxupé de $\mathrm{R} \$ 4.272 .073$, valor este que representa $1,78 \%$ em relação ao valor adicionado total a distribuir, o que significa que $1,78 \%$ do valor adicionado total foi retido pela cooperativa.

O grau de capacidade de produzir riqueza consiste na relação entre o valor adicionado líquido produzido pela entidade e o valor adicionado total a distribuir. Dessa forma, para o ano de 2012, a cooperativa foi capaz de gerar $69,16 \%$ do valor adicionado total, sendo que o restante, $30,84 \%$, indica a riqueza recebida em transferência pela entidade, 
sendo este o índice conhecido como grau de riqueza produzida em transferência.

O índice grau de contribuição na formação da riqueza de outras entidades consiste na soma dos insumos adquiridos de terceiros e as retenções e a sua relação com as receitas do mesmo período. Em $2012,92,88 \%$ da riqueza gerada pela cooperativa foi transferida para outras entidades.

O grau de participação dos cooperados na riqueza criada consiste na relação entre o valor líquido produzido pela cooperativa e o número total de cooperados, da mesma forma é realizado o cálculo do grau de participação dos colaboradores na riqueza criada. Em 2012, o grau de participação dos cooperados na riqueza criada foi de $\mathrm{R} \$ 17.783,94$, o que representa a contribuição per capita dos cooperados da cooperativa na riqueza por ela gerada. Assim como o grau de participação dos colaboradores na riqueza criada foi de uma contribuição per capita de $\mathrm{R} \$ 86.182,97$ em relação à riqueza gerada pela cooperativa.

O grau de contribuição dos ativos na geração de riqueza, em 2012, foi de $6,98 \%$, evidenciando uma contribuição dos ativos da cooperativa na geração de riqueza dela, sendo esta uma medida do potencial que a entidade tem em gerar riqueza, de acordo com Laureano (2000) e Dalmácio (2004).

O grau de contribuição do patrimônio líquido na geração de riqueza indica o quanto a empresa obteve de valor adicionado total em relação ao capital próprio, apresentando o potencial do capital próprio para a geração de riqueza de uma entidade (LAUREANO, 2000; DALMÁCIO, 2004). Para o ano de 2012, para a Cooxupé, o grau de contribuição do patrimônio líquido foi de $32,83 \%$.

\section{Considerações finais}

O presente artigo investigou qual a agregação de valor e a distribuição de riqueza de uma cooperativa de cafeicultores. Identificou-se que a cooperativa agrega valor aos associados tanto na distribuição direta de numerários aos associados e no aumento de capital como na prestação de serviços e subsídios aos cooperados. O valor total médio de benefícios recebido por cooperado para os anos de 2010, 2011 e 2012 foi respectivamente, $\mathrm{R} \$ 6.463,47, \mathrm{R} \$$ $6.008,99$ e $\mathrm{R} \$ 8.166,69$. O aumento de $36 \%$, de 2011 a 2012, se deu, em sua maioria, pelo benefício indireto de granelização.
Em relação a queda no faturamento da cooperativa de cafeicultores, em 2012, a qual afeta a sobra e a participação das sobras no valor adicionado total a distribuir, não foi observada na análise dos benefícios totais proporcionados aos associados.

Os benefícios afetados diretamente pela redução das sobras foram a distribuição de numerários e o aumento de capital, devido ao fato de o cálculo estar diretamente relacionado com o valor das sobras, sendo que ambos os valores correspondem a $10 \%$ das sobras líquidas do período. Enquanto, em 2011, o valor médio dos benefícios citados foi de $\mathrm{R} \$$ 880,68 cada um, em 2012, o valor médio de cada um dos benefícios foi de $\mathrm{R} \$ 458,66$.

Verifica-se, pela análise vertical de cada ano, que os benefícios diretos proporcionados pela cooperativa aos associados diminuíram enquanto que os benefícios indiretos tem aumentado. Os benefícios diretos representaram em 2010, 2011 e 2012 respectivamente $77,29 \%, 66,19 \%$ e $50,88 \%$ em relação ao total de benefícios de cada ano e, os benefícios indiretos representaram em 2010,2011 e 2012 respectivamente $49,12 \%, 33,81 \%$ e 22,71 em relação ao total de benefícios de cada ano.

Assim, observa-se na análise dos três anos estudados uma tendência, podendo indicar uma estratégia de proporcionar na mesma proporção benefícios diretos e indiretos.

Em 2012, a cooperativa de cafeicultores obteve um valor adicionado total (riqueza gerada total) de aproximadamente $\mathrm{R} \$ 237$ milhões, dos quais 69,16\% foram gerados pela própria cooperativa, evidenciando a capacidade dela em gerar riqueza. A cooperativa contribuiu, em 2012 , com $92,88 \%$ na formação da riqueza de outras entidades. É válido ressaltar que como os insumos adquiridos, em sua maioria, correspondem às commoditties compradas de seus associados, parte do índice consiste na distribuição de riqueza a eles.

Em 2012, o valor adicionado total distribuído pela cooperativa, como já mencionado, foi de aproximadamente R \$ 237 milhões. Foram distribuídos aos colaboradores $35,59 \%$ do total de valor adicionado, ao governo foram distribuídos $10,17 \%$, a terceiros, $26,26 \%$ e às sobras líquidas, $7,97 \%$. Observa-se que a maior participação na riqueza gerada se dá pelos colaboradores, que participam de mais de um terço da riqueza total gerada.

O estudo de caso da cooperativa de cafeicultores comprovou que a riqueza gerada pela cooperativa é 
distribuída e, que essa distribuição de riqueza chega ao cooperado, por meio dos benefícios diretos e indiretos que a cooperativa proporciona aos produtores rurais associados. Esses benefícios agregam valor e geram riqueza aos cooperados, dessa forma, conclui-se que a cooperativa realiza o seu papel fundamental, ou seja, é uma organização econômica intermediária que existe com o objetivo de responder aos anseios e às necessidades dos produtores rurais associados a ela. Sendo que sua estratégia consiste em agregar valor aos associados tanto na distribuição de numerários e no aumento de capital como na prestação de serviços e subsídios à eles.

\section{Referências}

\section{ALIANÇA COOPERATIVA INTERNACIONAL} (International Cooperative Alliance [ICA]. (2015). What is a Co-operative? Disponível em: <http://ica.coop/en/what-co-operative>. Acesso em: 13/01/2016.

BIALOSKORSKI NETO, Sigismundo. Economia e Gestão de Organizações Cooperativas. 2. ed. São Paulo: Atlas, 2012.

; NAGANO, Marcelo Seido; MORAES, Marcelo Botelho da Costa. Utilização de redes neurais artificiais para avaliação sócioeconômica: uma aplicação em cooperativas. Revista de Administração (USP), São Paulo, v. 41, n. 1, p. 59-68, 2006.

; PINTO, Anelise Krauspennhar. Evolução do Agronegócio e do Cooperativismo Agropecuário: uma análise comparativa de desempenho e impacto econômico. In: ENCONTRO BRASILEIRO DE PESQUISADORES EM COOPERATIVISMO, 2, 2012, Porto Alegre. Anais... Porto Alegre, 2012.

CANÇADO, Airton Cardoso; SOUZA, Maria de Fátima Arruda; CARVALHO, Jacqueline Elisa Furtado Barreto de; IWAMOTO, Helga Midori. Desfazendo um mal entendido: Discutindo a diferença entre lucros e sobras. Administração Pública e Gestão Social. Viçosa, v. 5, n. 1, p. 56-69, 2013.
CONSOLI, Matheus Alberto; MARINO, Matheus Kfouri. Distribuidores e Cooperativas: análises e impressões (parte 2). 2013. Disponível em: <http://www.agrodistribuidor.com.br/up_arqs/ pub_20130408152754_08deabril.pdf > Acesso em: 20/07/2013.

DALMÁCIO, Flávia Zóboli. Indicadores para Análise da Demonstração do Valor Adicionado. Revista Brasileira de Contabilidade, Brasília, DF, v. 1, n.1, p. 89-97, 2004.

DE LUCA, Márcia Martins Mendes. Demonstração do Valor Adicionado: do cálculo da riqueza criada pela empresa ao valor do PIB. São Paulo: Atlas, 1998.

FERREIRA, Marco Aurélio Marques; BRAGA, Marcelo José. Diversificação e Competitividade nas Cooperativas Agropecuárias. Revista de Administração Contemporânea, vol.8, n.4, p. 33-55, 2004.

GIL, Antonio Carlos. Como elaborar projetos de pesquisa. São Paulo: Atlas, 1999.

INSTITUTO BRASILEIRO DE GEOGRAFIA E ESTATÍSTICA - IBGE. Série Relatórios Metodológicos. Brasil, 2. ed., vol. 24, 2008. Disponível em:

$<$ http://www.ibge.gov.br/home/estatistica/ econo-

mia/contasnacionais/2008/SRM_contasnacionai s.pdf>. Acesso em: 23/07/2013.

KROETZ, César Eduardo; COSENZA, José Paulo. Considerações sobre a eficácia do valor adicionado para a mensuração do resultado econômico e social. In: IX Convenção de Contabilidade do Rio Grande do Sul, 2003, Gramado, RS. Anais.

LAUREANO, Wagner Deodato. Analisando a demonstração do valor adicionado. Revista Brasileira de Contabilidade, Brasília, n. 122, p. 38-43, mar./abr. 2000.

MANDAL, Niranjan; GOSWAMI, Suvarun. Value Added Statement (VAS) - A critical analysis. Great Lakes Gerald. Chennai, v. 2, n. 2, p. 98120, 2008. 
MAGALHÃES, Luzia Eliana Reis; ORQUIZA, Liliam Maria. Metodologia do trabalho científico: elaboração de trabalhos. Curitiba: Fesp, 2002.

MATTAR, Fauze Najib. Pesquisa de marketing: metodologia, planejamento. São Paulo: Atlas, 1999.

\section{ORGANIZAÇÃO DAS COOPERATIVAS NO}

BRASIL -OCB. (2015). [online] Disponível em:〈http://www.brasilcooperativo.coop.br/site> Acesso em: 10/01/2015.

PRESNO, Nora. As cooperativas e os desafios da competitividade. Estudos Sociedade e Agricultura, Rio de Janeiro, 2001, p. 119-144. Disponível em: <http://r1.ufrrj.br/esa/art/200110-119144.pdf>. Acesso em: 05/07/2013.

SANTOS, Ariovaldo dos. Demonstração do Valor Adicionado: como elaborar e analisar a DVA. São Paulo: Atlas, 2003.

SEXTON, Richard J. Cooperatives and the forces shaping agricultural marketing. American Journal of Agricultural Economics. Menasha, vol. 68, n. 5, p. 1167-1172, 1986.

TINOCO, João Eduardo Prudêncio. Balanço Social: uma abordagem de transparência e da responsabilidade pública das organizações. 3. ed. São Paulo: Atlas, 2006.

VIEIRA, Patrícia dos Santos; SANTOS, Ariovaldo dos. Um estudo empírico sobre a carga tributária das sociedades cooperativas agropecuárias a partir da demonstração do valor adicionado. In: Congresso USP de Controladoria e Contabilidade. 7, 2007, São Paulo.

ZYLBERSTAJN, Décio. Administração de sistemas de base agrícola: análise de fatores críticos. Revista de Administração. São Paulo, vol. 48, n. 2, p. 203-207, 2013. 